\title{
NUMERICAL SIMULATION OF COUPLED THERMO-HYDRO- MECHANICAL PROCESSES IN FREEZING SOILS
}

\author{
MAXIM S. ZHELNIN ${ }^{1}$, ANASTASIIA A. KOSTINA ${ }^{2}$, OLEG A. PLEKHOV ${ }^{3}$ AND \\ LEV Y. LEVIN ${ }^{4}$
${ }^{1}$ Institute of Continuous Media Mechanics of the Ural Branch of the Russian Academy of Sciences Ac. Korolev st., 1, Perm, 614013, Russia zhelnin.m@icmm.ru, http://www.icmm.ru/index.html
${ }^{2}$ Institute of Continuous Media Mechanics of the Ural Branch of the Russian Academy of Sciences Ac. Korolev st.,1, Perm, 614013, Russia kostina@icmm.ru,http://www.icmm.ru/index.html
${ }^{3}$ Institute of Continuous Media Mechanics of the Ural Branch of the Russian Academy of Sciences Ac. Korolev st., 1, Perm, 614013, Russia poa@icmm.ru, http://www.icmm.ru/index.html
${ }^{4}$ Mining Institute of the Ural Branch of the Russian Academy of Sciences
Sibirskaja st.,78a, Perm, 614007, Russia
aerolog_lev@mail.ru,https://www.mi-perm.ru/ru/

Key words: Artificial Ground Freezing, Frost heave, Water Migration, THM modelling.

\begin{abstract}
In the study a thermo-hydro-mechanical model of freezing of saturated soil is presented, with focus on numerical simulation of artificial ground freezing (AGF). Artificial freezing of saturated soils induces such process in the soils as water migration, frost heave and consolidation which can have an effect on the freezing process and surrounding areas. To take into account the important from geotechnical point of view processes the thermo-hydromechanical model was developed. The model is based on the fundamental balance equations of continuum media mechanics. The Clausius-Clapeyron equation and constitutive relations of poromechanics are used for describing a relationship between pore pressure, temperature, stress and strain fields. Also an inelastic strain is included accounting for an effect of frost heave. The equations of the model were implemented in Comsol Multiphysics ${ }^{\circledR}$ software and solved using the finite element method relative to variables of porosity temperature and displacement. Numerical simulation of artificial freezing of a soil stratum for a vertical shaft sinking was carried out. A mesh convergence of numerical solution was analyzed. Results of the simulation have shown the model enables to describe a frozen wall formation with a coupled change of porosity, water pore pressure, volumetric strain and mean stress.
\end{abstract}

\section{INTRODUCTION}

A research of artificial freezing of saturated soils is largely caused by interests of 
underground engineering. To construct tunnels and mine shafts under hard hydrogeological conditions some activities for soil reinforcement have to be conducted. Artificial Ground Freezing (AGF) is an effective engineering technique which enables to prevent failure of an excavation and its water flooding [1]. A decrease in ground temperature leads to freezing of pore water and generating ice crystals which improve strength and stiffness properties of the freezing ground and obstruct a water flow in the pore space. Therefore, frozen ground serve as waterproof temporary shield around a constructed excavation [2].

Currently, computer modeling is started to apply for predicting an evolution of the ground freezing process and controlling freezing regimes. However numerical simulation of freezing of saturated soils is a complex problem involving an interaction between thermal, hydraulic and mechanical processes. One of the results of the interaction is an occurrence of cryogenic suction which induces water migration towards the freezing zone. To describe an influence of the water migration on the freezing process a thermo-hydraulic models are developed. Harlan [3] was proposed one of the first model which enables to compute heat and mass transfer in freezing soil. The model includes the Richards equation and a heat conduction equation with apparent heat capacity coefficient. Numerical algorithm for solving the equations is developed for one-dimensional transient problem using the finite difference method. The Harlans's model provided a basis for derivation of many mathematical models of soil freezing [4]. Modern thermo-hydraulic models are able to be applied for simulation of ground freezing process in geotechnical applications. A thermo-hydraulic model of Tan X et al. [5] was used for study of soil freezing around a tunnel. Huang S. et al. [6] developed a model for AGF for tunneling excavation around a tunnel was suction is taken into account evaluating water velocity. To conservation equations of the model the finite

In freezing soil water migration contributes to frost heaving of the soil in the frozen zone

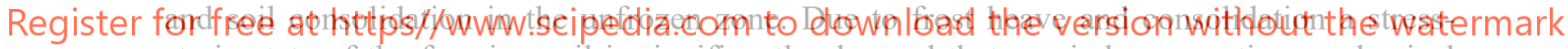
strain state of the freezing soil is significantly changed that can induce negative mechanical effect on surrounding areas. To take into account a mechanical behavior of freezing soil a thermo-hydro-mechanical models are developed [7-10]. Bekele et al. applied their model for numerical study of an effect of freezing soil on a buried pipeline [7]. A model proposed by Arzanfudi and Al-Khoury is used for simulation of freezing and thawing of soil around an energy pile [8]. Large-scale simulation of AGF for tunneling excavation is performed using models developed by Zhou and Meschke [9], Tounsi et al. [10]. The thermo-hydromechanical models in addition to mass balance and energy conservation equations include the momentum balance equation and constitutive relations establishing a relationship between stress and strain fields. Heat and mass transfer in the models are described similar to thermohydraulic models. To incorporate cryogenic suction, the Clausius-Clapeyron equation is adopted. A stress-strain state of freezing soil is simulated using constitutive relations of poromechanics theory and a conception of effective stress. The effective stress tensor is written in the Bishop form that enables to take into account an effect of ice pore pressure on the rigid skeleton. Also a state equation is included in the model to estimate an influence of pore pressure and volumetric strain on soil porosity. In $[9,10]$ numerical solution of the governing equations is performed using the finite element method. In [7] numerical algorithm 
is developed based on the isogeometric analysis. Spatial discretization scheme proposed in [8] includes the finite element method for the balance equations and the extended finite element method for the cryogenic suction equation. In [8] it is noted that solution of the cryogenic suction equation using the finite element method could lead to oversmooth pressure distribution.

In the abovementioned thermo-hydro-mechanical models the mass balance equation is solved relative to pressure variable. Another approach was proposed by Lai et al. [11]. In the model solution of the mass balance equation is conducted relative to soil porosity. Based on experimental data of one-side freezing test it has been shown that the model enables to accurately describe porosity evolution induced by frost heave and consolidation of freezing soil. However, the model can be applied for simulation of one-dimensional freezing process. Following to approach of Lai et al. [11] in the present study a three-dimensional thermohydro-mechanical model of freezing of saturated soil is developed. In the developed model to simulate water migration due to cryogenic suction, the Darcy law and the Clausius-Clapeyron equation are adopted. Latent heat of the phase change is incorporated in the energy conservation equation through volumetric heat source. Mechanical behavior of freezing soil is described within the framework of the Coussy poromechanics $[9,10,12]$. As frost heave induces a significant volumetric expansion of freezing soil, constitutive relation for inelastic volumetric strain is included. The governing equations of the model were implemented in the finite-element software Comsol Multiphysics $(B$. The developed model was used for numerical simulation of a large-scale geotechnical problem related to application of AGF for a vertical shaft sinking in a potash deposit. 2 THERMO-HYDRO2.1 Mathematical formulation
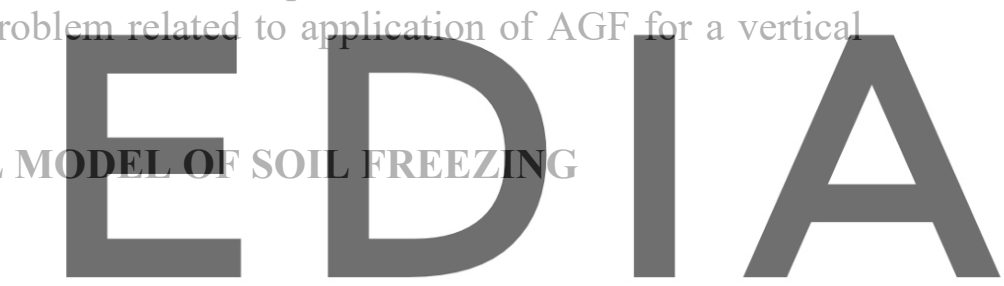

In the developed thermo-hydro-mechanical model of freezing of saturated soil, the soil is

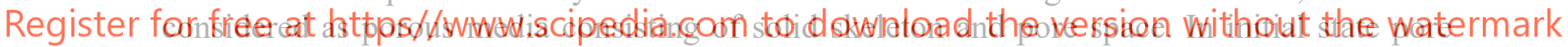
space contains only water phase $(l)$. During freezing the pore water converts into the ice phase (i). To simulate thermo-hydro-mechanical processes arising in the freezing soil, the mass balance equation, the energy conservation equation and the momentum balance equation are derived within the continuum mechanics approach. A couple between heat transfer and water migration is provided by temperature dependent ice saturation and hydraulic conductivity, the Clausius-Clapeyron equation, convective heat transfer. An interaction between a change of porosity and a stress-strain state of the soil is established according to Coussy poromechanics. Thermo-mechanical coupling is given by a dependence of mechanical properties on temperature and thermal strain.

Mathematical formulation of the governing equation of the model is written as following. The mass balance equation is

$$
\frac{\partial\left(\rho_{l} S_{l} n\right)}{\partial t}+\frac{\partial\left(\rho_{i} S_{i} n\right)}{\partial t}+\operatorname{div}\left(\rho_{l} \mathbf{v}_{l}\right)=0
$$

The momentum balance equation is

$$
\operatorname{div} \boldsymbol{\sigma}+\boldsymbol{\gamma}=0
$$


The energy conservation equation is

$$
C \frac{\partial T}{\partial t}-\operatorname{div} \lambda \operatorname{grad} T+C \mathbf{v}_{l} \cdot \operatorname{grad} T=L \rho_{i} \frac{\partial\left(n S_{i}\right)}{\partial t} .
$$

In the equations $\rho_{j} S_{j} n$ is the mass content of water $(j=l)$ and ice $(j=i)$ at time $t, \rho_{j}$ is the density and $S_{j}$ is saturation of the phase $j, n$ is the porosity, $\mathbf{v}_{l}$ is the velocity of water relative to the solid skeleton, $\boldsymbol{\sigma}$ is the total stress tensor, $\gamma$ is the unit weight of the porous medium, $T$ is the temperature, $C$ is the volumetric heat capacity and $\lambda$ is the thermal conductivity of the porous media, $L$ is latent heat of the phase transition.

The ice saturation $S_{i}$ is given by an empirical function of the temperature $T$ :

$$
S_{i}= \begin{cases}1-\left[1-\left(T-T_{p h}\right)\right]^{\alpha}, & T \leq T_{p h}, \\ 0 & T>T_{p h}\end{cases}
$$

where $T_{p h}$ is the freezing temperature of pore water and $\alpha$ is an experimental parameter. The water saturation $S_{l}$ can be obtained from the condition of fully saturated porous media.

To evaluate the water velocity $\mathbf{v}$, the Darcy law is adopted

$$
\mathbf{v}_{l}=-k \operatorname{grad} \psi
$$

where $k$ is the hydraulic conductivity and $\psi$ is the soil-water potential depended on the pore water pressure $p_{l}$. The hydraulic conductivity $k$ is expressed through function of the

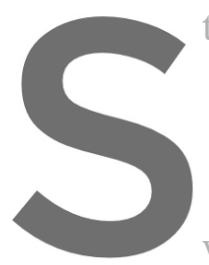
temperature $T$ :

where $k_{0}$ is the hydraulic
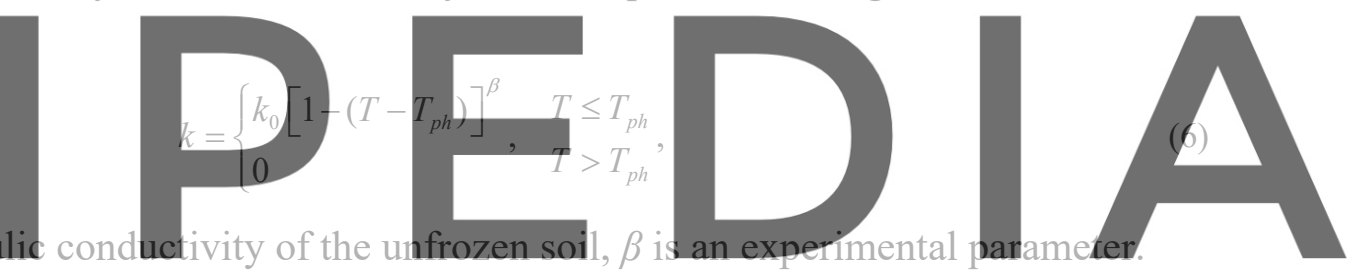

The total stress tensor is written according to effective stress principle as [12]

Register for free at https//www.scipedia.com to'dopwnload the version without the watermark

where $\sigma^{\prime}$ is the effective stress, $p$ is the eqivalent pore pressure, $b$ is the effective Biot coefficient, $\mathbf{I}$ is the identity tensor. The effective stress $\boldsymbol{\sigma}^{\prime}$ is expressed through the elastic strain $\boldsymbol{\varepsilon}^{e}$ using the Hooke's law

$$
\boldsymbol{\sigma}^{\prime}=\left(K-\frac{2}{3} G\right) \varepsilon_{v o l}^{e} \mathbf{I}+2 G \boldsymbol{\varepsilon}^{e},
$$

where $K$ is the effective bulk modulus, $G$ is the effective shear modulus, $\varepsilon_{v o l}^{e}$ is the volumetric part of the tensor $\boldsymbol{\varepsilon}^{e}$.

According to the principle of the additive decomposition of the total strain $\boldsymbol{\varepsilon}$, the elastic strain $\boldsymbol{\varepsilon}^{e}$ is written as

$$
\boldsymbol{\varepsilon}^{e}=\boldsymbol{\varepsilon}-\boldsymbol{\varepsilon}^{\text {th }}-\boldsymbol{\varepsilon}^{i n},
$$

where $\boldsymbol{\varepsilon}^{\text {th }}$ is the thermal strain, $\boldsymbol{\varepsilon}^{\text {in }}$ is inelastic strain. The total strain $\boldsymbol{\varepsilon}$ is defined through the displacement vector $\mathbf{u}$ according to the infinitesimal strain theory.

The equivalent pore pressure $p$ is assumed to be weighted sum of the pore water pressure $p_{l}$ 
and the pore ice pressure $p_{i}$ :

$$
p=\chi p_{l}+(1-\chi) p_{i}
$$

where $\chi$ is a parameter, such that $\chi=\left(1-S_{i}\right)^{1.5}$.

The pore water pressure $p_{l}$ is expressed from (11) and the Clausius-Clapeyron equation as follows [11]

$$
p_{l}=\frac{(1-\chi)\left(\rho_{l}-\rho_{i}\right) p_{h y d r}+(1-\chi) \rho_{i} \rho_{l} L \ln \left(T / T_{p h}\right)+\rho_{l} p}{\chi \rho_{l}+(1-\chi) \rho_{i}},
$$

where $p_{h y d r}$ is the initial pressure.

To evaluate the pore pressure $p$ a state equation provided by the Coussy poromechanics is used

$$
p=N\left(n-n_{0}-b \varepsilon_{\text {vol }}^{e}+3 \alpha_{T}\left(b-n_{0}\right)\left(T-T_{0}\right)\right),
$$

where $n_{0}$ is the initial porosity, $N$ is the effective Biot tangent modulus.

The inelastic strain $\varepsilon^{i n}$ is responsible for volumetric expansion of the freezing soil on effect of the frost heave. Ghoreishian Amiri et al. [13] are noted that high cryogenic suction can lead to inelastic volumetric strain in freezing soil. In the study a condition of exceeding of cryogenic suction its threshold value is used as yield criterion. According to the approach we introduce the volumetric inelastic strain $\varepsilon_{v o l}^{i n}$ related to tension of freezing soil due to ice

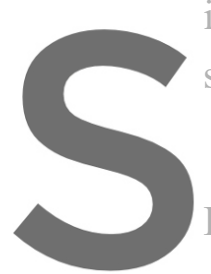
segregation:

In contrast of [13] we determine yield criterion

$$
F=A \sigma_{m}^{\prime}-B
$$
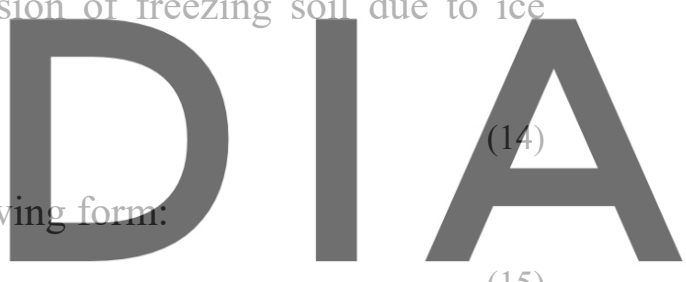

(15)

Register førtfiree at https//www.scipedia.com to download the version without the watermark

$$
A=\frac{6 c \cos \varphi}{\sqrt{3}(3-\sin \varphi)}, \quad B=\frac{2 \sin \varphi}{\sqrt{3}(3-\sin \varphi)},
$$

where $\sigma_{m}^{\prime}$ is the effective mean stress, $c, \varphi$ are cohesion and friction angle of soil in an unfrozen state. The strain $\varepsilon_{v o l}^{i n}$ is computed from (14) according to the associated flow rule of plasticity. It should be noted that the inelastic strain is induced by a formation of the massive cryogenic structure and thin ice lenses in saturated soil during freezing. A growth of thick ice lenses are not considered.

The effective mechanical properties are computed as in [9]:

$$
X=(1-\chi) X_{f r}+\chi X_{u n},
$$

where $X$ is the effective value, $X_{f r}$ and $X_{u n}$ are values for the frozen and the unfrozen states.

Thermophysical properties are determined as in [14]. 


\subsection{Computer implementation}

The partial differential equation of the developed model is solved by the Comsol Multiphysics ${ }^{\circledR}$ software. Porosity $n$, displacement vector $\mathbf{u}$ and temperature $T$ were considered as primary field variables. For spatial discretization of the equations the finite element method was applied. Approximation of the field variables was performed by linear Lagrange shape functions. Temporal discretization was conducted according to the backward Euler scheme.

\section{NUMERICAL SIMULATION OF ARTIFICIAL GROUND FREEZING}

The developed model (1)-(17) was used for numerical simulation of AGF for a vertical shaft sinking in a potash deposit in the Republic of Belarus. The deposit is exploited by the Belaruskali Company.

The simulation was nerformed for a silt stratum laving at the denth of $50-58 \mathrm{~m}$. The thermal regimes and design parameters of artificial freezing were specified on the basis of the technical and design documentation of the Belaruskali Company for construction of vertical mine shafts.

Figure 1a presents the arrangement of freezing wells around the project excavation. The number of wells is forty-one. The wells are located in a circle with a radius of $8.25 \mathrm{~m}$. The radius of the freezing wells is $7.310^{-2} \mathrm{~m}$. The distance between two wells is $1.11 \mathrm{~m}$.
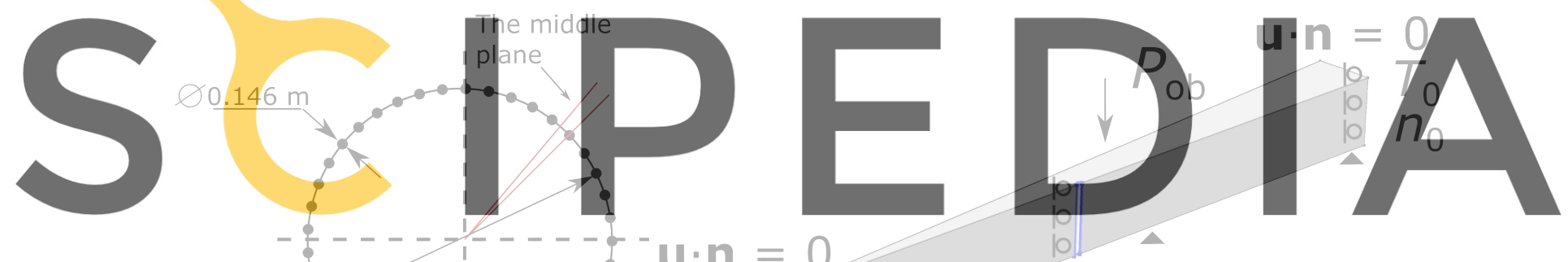

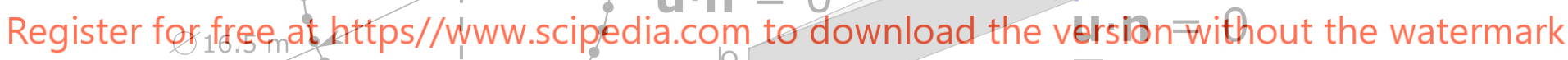

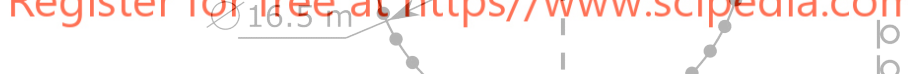

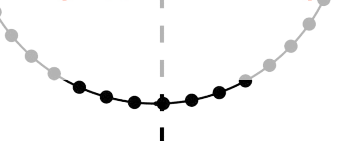

(a)

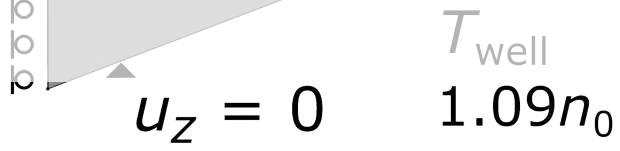

(b)

Figure 1: The layout of freezing wells. Red lines border the considered area (a). The geometry of the computational domain and the layout of the boundary conditions (b).

Neglecting inclination of the freezing wells from vertical direction and due to symmetry conditions we can study the artificial freezing process in a domain bounded by two symmetry planes. In Figure 1a projections of the symmetry planes are shown in Figure 1a with red lines. The first plane passes through the center of a freezing well. The second plane passes through the middle of the distance between the chosen well and the neighboring one. In what follows, we will call this plane the middle plane.

The computational domain and a layout of the boundary conditions are shown in Figure 1b. The distance from the center of the projected excavation to the outer boundary is $16.5 \mathrm{~m}$. 
The top boundary is subjected to the overburden pressure $P_{o b}=1 \mathrm{MPa}$. On the bottom boundary the vertical displacement $u_{z}$ is fixed. On boundary of the freezing well and the outer boundary the displacement $\mathbf{u}$ is constrained in the horizontal direction. Also the displacement $\mathbf{u}$ is constrained in the horizontal direction at the inner edge due to the symmetry condition. Temperature $T$ and porosity $n$ are given on the boundary of the freezing well and the outer boundary. On the freezing well boundary the temperature $T$ is equal to the freezing temperature $T_{\text {well }}$, the porosity is equal to $1.09 n_{0}$. Minimal freezing temperature is $-20 \mathrm{C}$. On the outer boundary temperature $T$ and porosity $n$ on the surface are supposed to be constant and equal to the initial values $T_{0}=10 \mathrm{C}$ and $n_{0}=0.32$.

To obtain a numerical solution the computational domain was divided on triangular prism elements such that lateral boundary of the prism elements is parallel to the vertical direction. Near the freezing well boundary the computational mesh was refined.

Figure 2 shows results of an analysis of convergence of numerical solution dependent on a mesh size. The average size havr of triangular base of elements of a reference mesh is $0.19 \mathrm{~m}$. The number of elements in the reference mesh is 22374. The mesh enlargement was performed using a scale procedure with coefficients of 1.1, 1.3, 1.5, 2.0, 4.0.

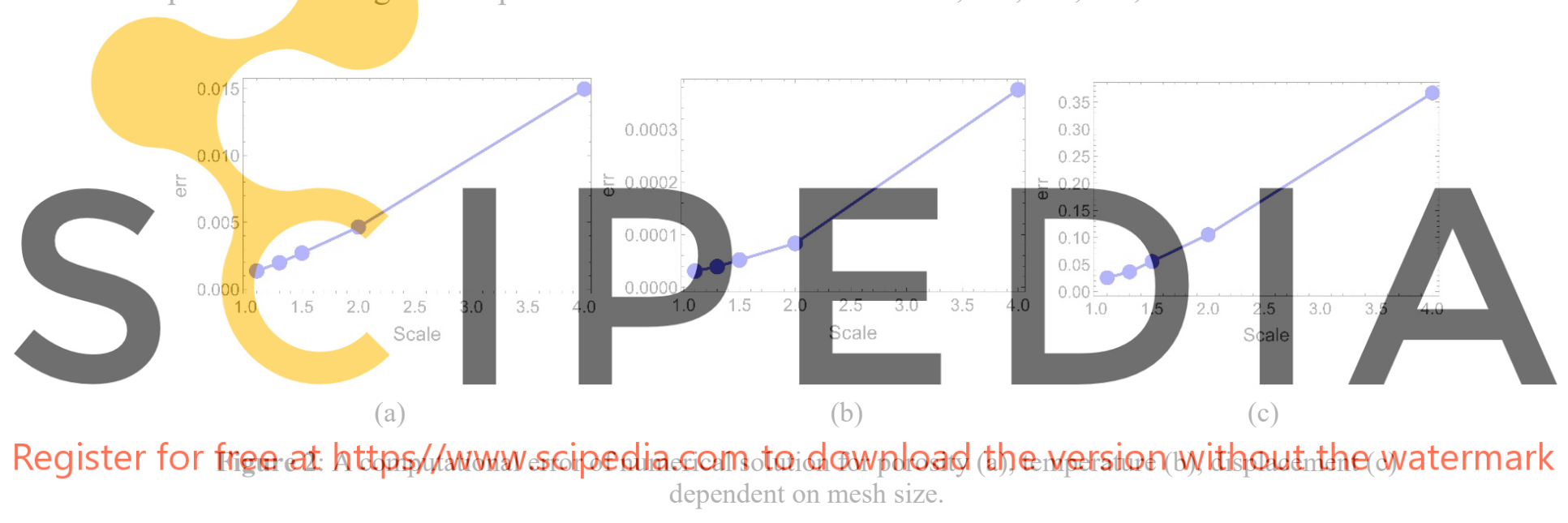

A computational error was estimated as follows

$$
e r r=\frac{\int_{0}^{t} \int_{\Omega}\left(v a r_{e}-v a r\right)^{2} \mathrm{~d} V \mathrm{~d} t}{\int_{0}^{t} \int_{\Omega}\left(v a r_{e}\right)^{2} \mathrm{~d} V \mathrm{~d} t},
$$

where $\Omega$ is a computational domain, var corresponds to a numerical solution for one of the primary field variables which is the porosity $n$, the temperature $T$ and the displacement vector $\mathbf{u}$, vare $_{\text {e }}$ corresponds to a numerical solution obtained on the reference mesh. The simulation of the artificial freezing process was conducted for a time period of 140 days.

From Figure 2 it can be seen that the computational errors of all primary field variables decrease with reducing of size of the computational mesh. A mesh refinement in two times from scale coefficient 4 to 2 leads to a fast reduction of the errors for all variables. After that the errors slowly convergences to zero with decreasing the mesh size. Therefore, it can be 
concluded that proposed numerical scheme provides a convergent numerical solution of the set of the partial differential equations (1) - (3).

Figure 3 shows temperature $T$ distribution after 16, 38, 140 days of the freezing. The freezing process can be divided in two stages. In the first stage the freezing front propagates form the freezing well to the middle plane. At the end of the stage a closure of the frozen wall around the projected excavation is achieved. In the second stage a thickness of the frozen wall increases along with propagation of the freezing front to external surrounding soil.

Porosity $n$ distributions after 38, 70, 140 days of the freezing are presented in Figure 4. Due to intensive frost heave of the silt in the frozen zone the porosity raises by $22 \%$ compared to the initial value. As the freezing of original water content can induce a rise of porosity only by $9 \%$, it can be concluded that cryogenic suction causes a significant water migration to the

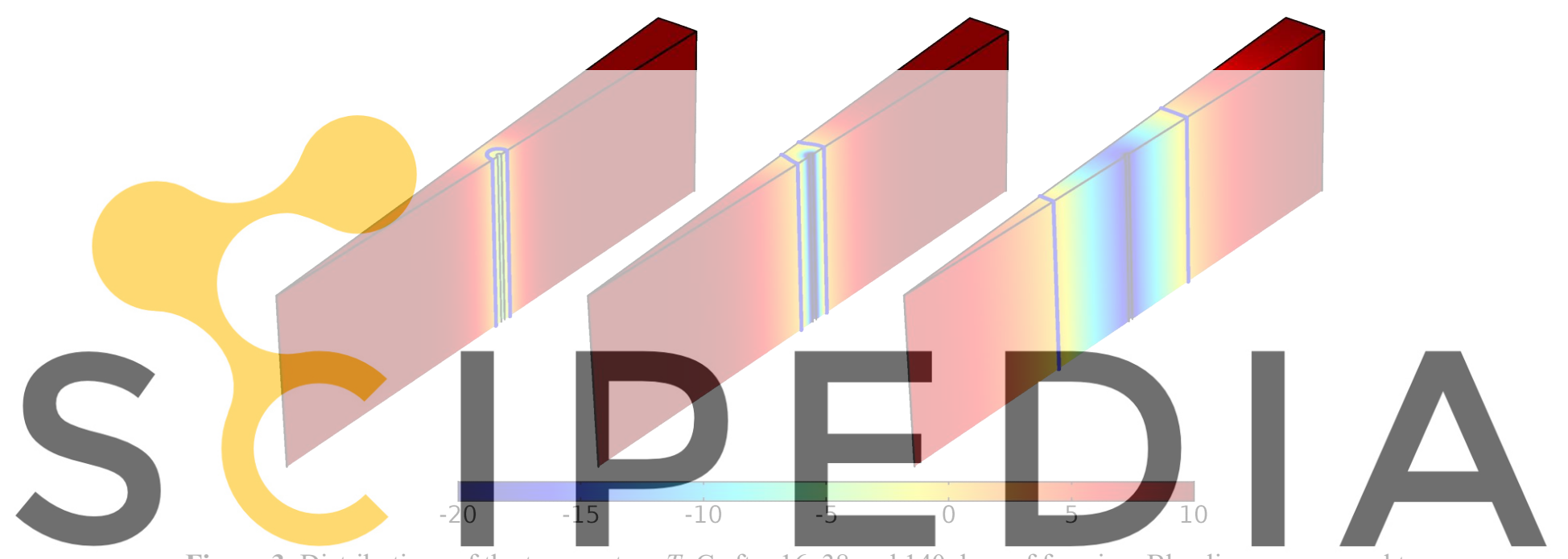

Figure 3: Distributions of the temperature $T$ C after 16, 38 and 140 days of freezing. Blue lines correspond to Register for free at https//www.scipedia.com to download the version without the watermark

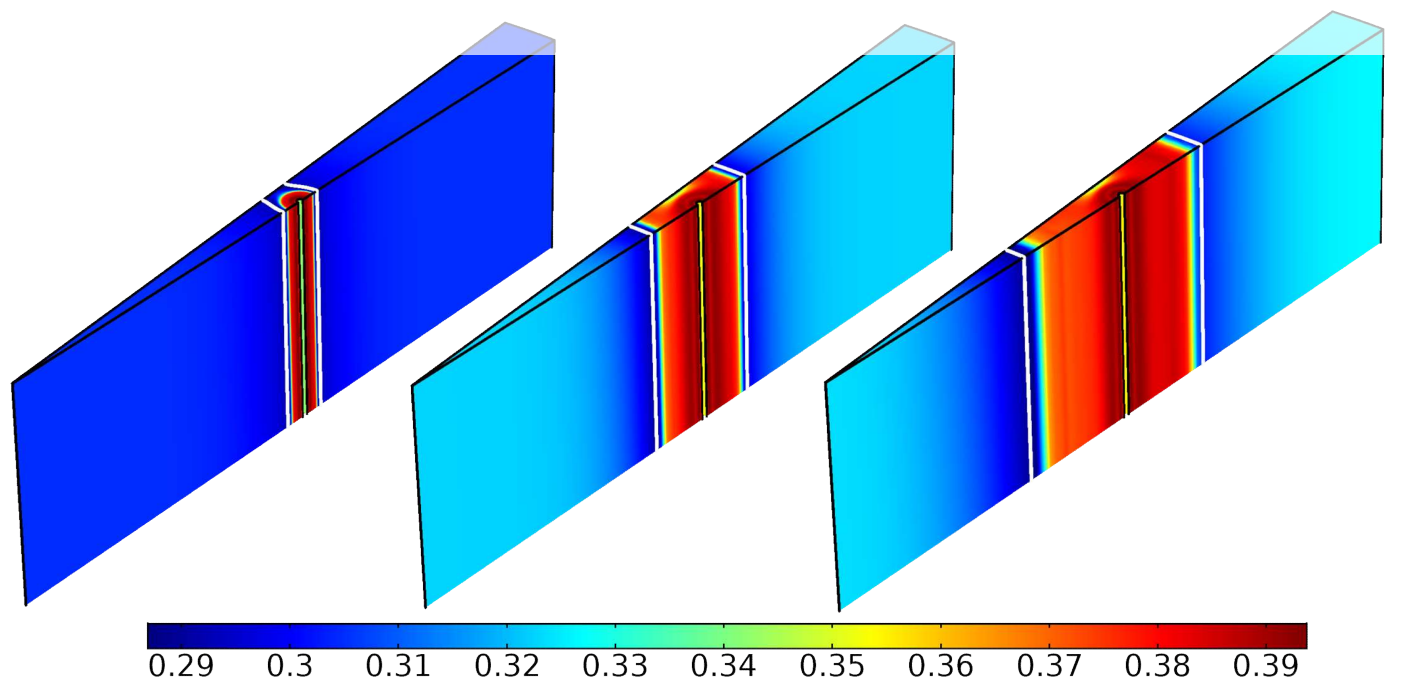

Figure 4: Distributions of the porosity $n$ after 38, 70 and 140 days of freezing. White lines correspond to the 
position of the freezing front.

frozen zone. Result of the water flow from the unfrozen zone to the frozen zone is a reduction of the porosity and soil consolidation near the freezing front. Besides, a region with reduced porosity arises adjoining to the middle plane. In the first stage of the freezing process cryogenic suction gives rise to water migration from the region to the freezing front. Therefore, when the freezing front reaches the middle plane in the region the porosity rises only by $5 \%$.

Figure 5 shows distribution of volumetric strain $\varepsilon_{v o l}$ and mean effective stress $\sigma_{m}^{\prime}$ after 70 days of the freezing. It can be seen a strong coupling between the porosity distribution and the stress-strain state of the soil. In the frozen zone a raise in the porosity is accompanied by a volumetric expansion of the solid skeleton and an increase in the mean stress that is typical for frost heave. Nevertheless, in the region with reduced porosity adjoining to the middle plain the volumetric strain and the mean stress remain negative because of a weak frost heave. In rest part of the frozen wall the mean stress reaches a tensile strength, so an inelastic volumetric strain evolves according to the yield criterion (15) and the associated flow rule. Near the sides of the frozen wall (white lines in Figures 4, 5) a decrease in the porosity is accompanied by volumetric shrinkage of the soil and a reduction of the mean stress, so the soil consolidates. Also it can be observed that unfrozen soil inside of the frozen wall is compressed more significantly than outside of the wall. It can be explained by an impact of

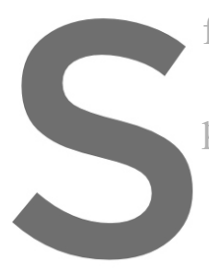
frost heave of soil duing the freezing.

\section{The consolidation} pressure $p_{l}$. Figure 6 s
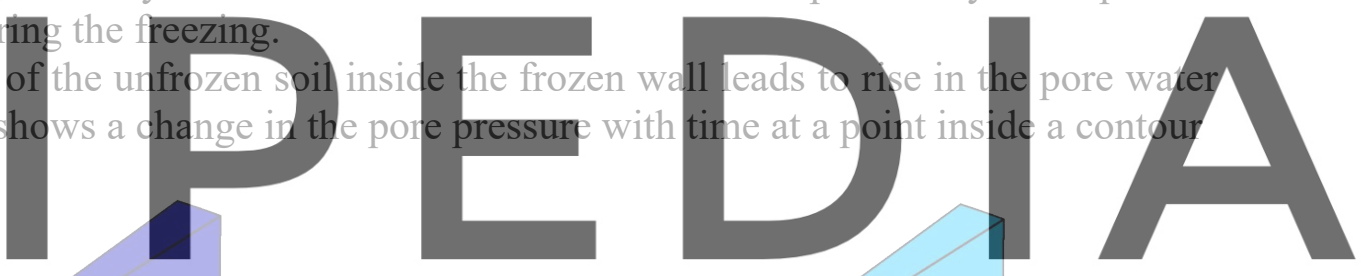

Register for free at https/hwww.scipedia.com to download the version without the watermark

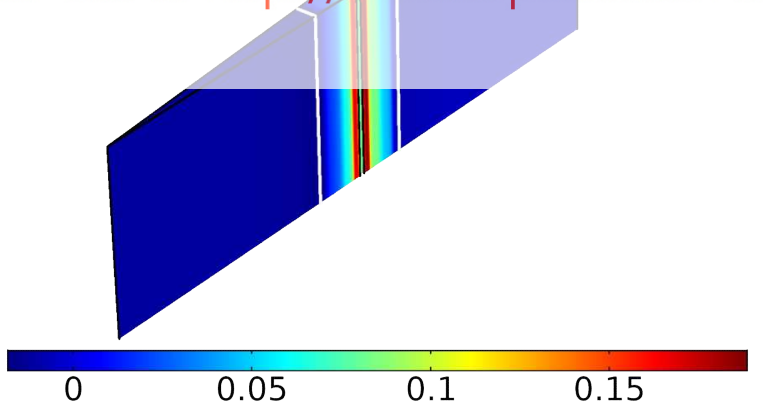

(a)

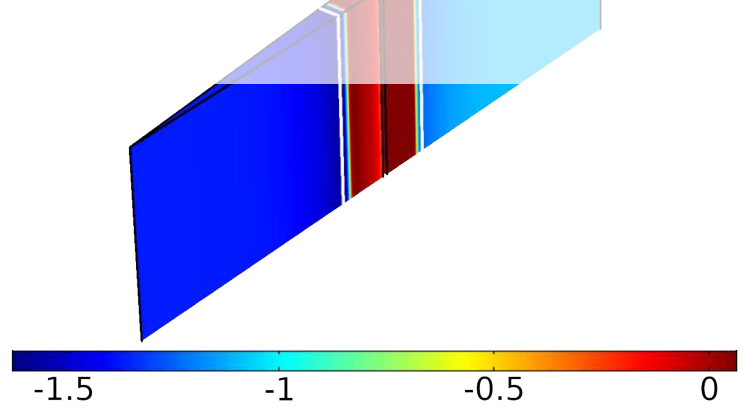

(b)

Figure 5: Distributions of the volumetric strain $\varepsilon_{v o l}$ (a) and the mean effective stress $\sigma_{m}^{\prime}$ (b) after 70 days of the freezing. White lines correspond to the position of the freezing front. 


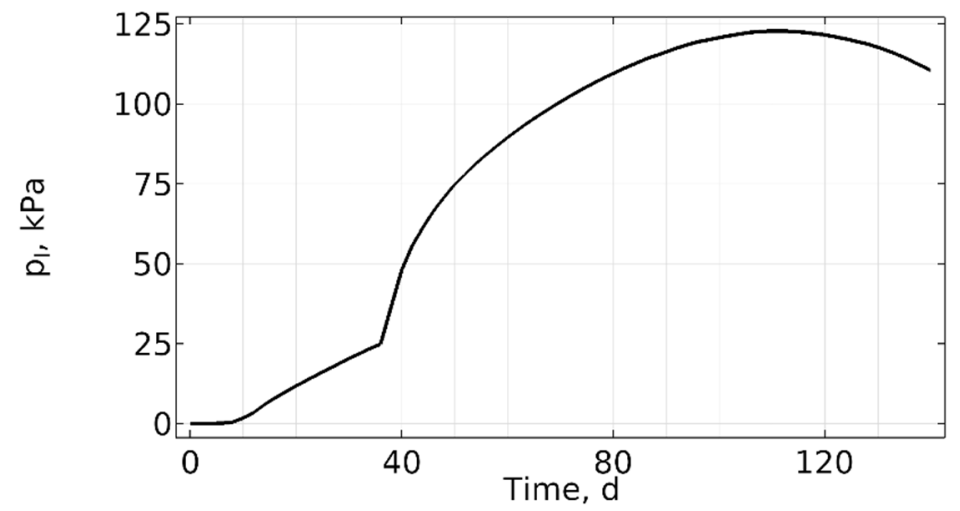

Figure 6: Temporal evolution of the water pore pressure at a point inside the contour of the freezing wells.

\section{of the freezing wells. It can be seen that in the first stage of the freezing the pore pressure slightly increases under a mechanical impact of the frozen soil. After achieving a closed frozen wall, the pore pressure rises abruptly since the mechanical impact on the unfrozen soil significantly increases and the pore water cannot outflow. Then the pore pressure monotonically rises until an effect of cryogenic suction exceeds the mechanical impact. Finally, water migration to the freezing front induces a decrease in the pore pressure.}

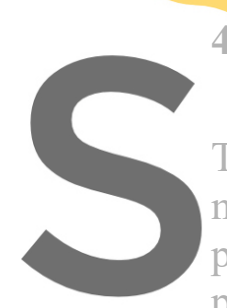

4 CONCLUSIONS

In the paper, a thern The model is based on momentum equation. provided thorough the poromechanics, volunne heat atd mass source the mo-hydro-mechanical nodel of freezing of sattrated soil is
the mass balance equation, the energy conservation equat
Che coupling between thermal, hydraulic and mochanical p
Clausius-Clapeyron equation, constitutive relations of the for describing a change of soil properties with temperature Also in the model a volumetric

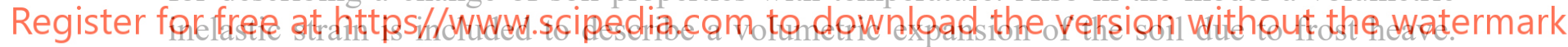

The equations of the model were implemented in the Comsol Multiphysics software and solved using the finite element method.

The proposed model was applied for numerical simulation of artificial freezing process of a soil stratum for a vertical shaft sinking. An analysis of the mesh convergence has shown that a use of the developed numerical scheme allowed one to obtain a convergent numerical solution of the equations of the model. Results of the performed numerical simulation demonstrated that the model is able to describe a frozen wall formation with considering such important phenomena such as water migration to the freezing front, frost heave in frozen zone and the soil consolidation in the unfrozen zone. It was shown that due to water migration an intensive frost heave evolves in the frozen zone. The frost heave leads to a rise in the porosity and inelastic volumetric expansion of the freezing soil. A water outflow from the unfrozen zone to the frozen zone contributes to soil consolidation near the sides of the frozen wall and in the region adjusting to the middle plane. After a closure of the frozen wall an increase in its thickness causes an abrupt rise of the pore water pressure in the unfrozen soil inside the wall due to a mechanical impact of the frozen soil. Nevertheless, during the freezing a strong 
cryogenic suction induces water migration to the inner side of the wall as a result the pore pressure decreases.

\section{ACKNOWLEDGEMENTS}

The reported study was funded by RFBR, project number 19-31-90107

\section{REFERENCES}

[1] Levin, L., Golovatyi, I., Zaitsev, A., Pugin, A., Semin, M.. Thermal monitoring of frozen wall thawing after artificial ground freezing: Case study of Petrikov Potash Mine. Tunnelling and Underground Space Technology (2021) 107:103685.

[2] Kostina, A., Zelnin, M., Plekhov, O., Panteleev, I., Levin, L., Semin, M. (2020). An Applicability of Vyalov's equations to ice wall strength estimation. Frattura ed Integrità Strutturale (2020) 14(53):394-405.

[3] Harlan, R.L. Analysis of coupled heat-fluid transport in partially frozen soil. Water Resources Research (1973) 9(5):1314-1323.

[4] Kurylyk, B.L., Watanabe, K. The mathematical representation of freezing and thawing processes in variably-saturated, non-deformable soils. Advances in Water Resources (2013) 60:160-177.

[5] Tan, X., Chen, W., Tian, H., Cao, J. Water flow and heat transport including ice/water phase change in porous media: Numerical simulation and application. Cold Regions Science and Technology (2011) 68(1-2):74-84.

[6] Huang, S., Guo, Y., Liu, Y., Ke, L., Liu, G. Study on the influence of water flow on temperature around freeze pipes and its distribution optimization during artificial ground freezing. Applied Thermal Engineering (2018) 135:435-445.

[7] Bekele, Y.W., Kyokawa, H., Kvarving, A.M., Kvamsdal, T., Nordal, S. Isogeometric analysis of THM coupled processes in ground freezing. Computers and Geotechnics (2017) 88:129-145.

[8] Arzanfudi, M.M. and Al-Khoury, R. Freezing-thawing of porous media: An extended finite element approach for soil freezing and thawing. Advances in Water Resources (2018) 119:210-226.

[9] Zhou, M.M. and Meschke, G. A three-phase thermo-hydro-mechanical finite element model for freezing soils. International journal for numerical and analytical methods in geomechanics (2013) 37(18):3173-3193.

[10] Tounsi, H., Rouabhi, A., Tijani, M., Guérin, F. Thermo-hydro-mechanical modeling of artificial ground freezing: application in mining engineering. Rock Mechanics and Rock Engineering (2019) 52(10):3889-3907.

[11] Lai, Y., Pei, W., Zhang, M., Zhou, J. Study on theory model of hydro-thermalmechanical inter-action process in saturated freezing silty soil. International Journal of Heat and Mass Transfer (2014) 78:805-819.

[12] Coussy, O. Poromechanics of freezing materials. Journal of the Mechanics and Physics of Solids (2005) 53(8):1689-1718.

[13] Ghoreishian Amiri, S.A., Grimstad, G., Kadivar, M., Nordal, S. Constitutive model for rate-independent behavior of saturated frozen soils. Canadian Geotechnical Journal, (2016) 53(10):1646-1657.

[14] Mu, S. and Ladanyi, B. 1987. Modelling of coupled heat, moisture and stress field in 
freezing soil. Cold Regions Science and Technology (1987) 14(3): 237-246. 